Article

\title{
Experimental Investigation on the Performance of Historical Squat Masonry Walls Strengthened by UHPC and Reinforced Polymer Mortar Layers
}

\author{
Bin Peng ${ }^{1, *(\mathbb{C}}$, Sandong Wei ${ }^{1}{ }^{\oplus}$, Libo Long ${ }^{2}$, Qizhen Zheng ${ }^{1}$, Yueqiang $\mathrm{Ma}^{2}$ and Leiyu Chen ${ }^{1}$ \\ 1 School of Environment and Architecture, University of Shanghai for Science and Technology, \\ Shanghai 200093, China; weis_usst@163.com (S.W.); zhengqz1@163.com (Q.Z.); \\ chenleiyu.2007@163.com (L.C.) \\ 2 Shanghai Construction Group, Shanghai 200080, China; longlibo001@126.com (L.L.); \\ mayueqiang001@126.com (Y.M.) \\ * Correspondence: BinPeng@usst.edu.cn; Tel.: +86-21-5527-5979
}

Received: 3 April 2019; Accepted: 24 April 2019; Published: 21 May 2019

check for updates

Featured Application: The proposed methods and techniques can be applied to strengthen historical masonry walls efficiently.

\begin{abstract}
Strengthening historical brick masonry walls is important because these walls are major load-bearing members in many architectural heritages. However, historical brick masonry has low elastic modulus and low strength, historical masonry walls are prone to surface treatment or other structural intervention, and some of the walls lack integrity. These characteristics make effective strengthening of historical masonry walls difficult. To address the issue, strengthening layers made up of ultra-high performance concrete (UHPC) are potentially useful. To investigate the strengthening effect of the UHPC layers, the authors constructed three squat walls using historical bricks and mortar collected from the rehabilitation site of a historical building, and strengthened two of the walls with a UHPC layer and a reinforced polymer mortar layer respectively. The three walls were broken down by horizontal cyclic force along with constant vertical compression, and then the unstrengthened one was strengthened in-situ by a UHPC layer and was tested again. The experimental results indicate that the UHPC layers significantly improved the in-plane shear resistance and cracking load of the squat walls, without decreasing the walls' ultimate deformation. They effectively strengthened both moderately and severely damaged historical masonry walls, because the UHPC filled the existing damages and improved the integrity of the masonry substrate. In addition, the UHPC layers intervened the historical walls less than the reinforced polymer mortar layer. Therefore, the UHPC layers are efficient in strengthening historical squat masonry walls.
\end{abstract}

Keywords: historical masonry wall; ultra-high performance concrete; strengthening; pseudo-static experiment

\section{Introduction}

Strengthening of historical masonry walls is critical for heritage reservation, because these walls are the major load-bearing members in many architectural heritages around the world. The topic has attracted intensive research [1-5]. Masonry walls can be strengthened by applying externally bonded layers or strips. The former covers the walls' surface entirely while the latter covers partially. Given appropriate strengthening designs, they would not intervene the target buildings significantly and would not influence the buildings' aesthetics. Therefore, they are also applicable for strengthening the historical buildings. The two methods can significantly reduce the working stress in regular masonry 
walls under different load cases, and then comprehensively rehabilitate the walls' performances [6-8]. However, special considerations deserve when they are used for the historical brick masonry walls [9].

First, it is difficult for the strengthening layers or strips to deform well with the masonry substrates, especially under high in-plane compression. Because the elastic modulus of the historical masonry substrate is extraordinary lower than that of the strengthening layers or strips. Under the circumstance, the layers or strips do not activate much of their strength, and then the resistance of the strengthened walls can still be low [10]. In addition, the stiffness of the strengthened walls can also be low, resulting in risks of unacceptable lateral deformation or even collapse during earthquakes. Although the issues can be relieved by prestressing the strengthening strips, it requires a large anchor length of the strips on the weak historical masonry substrates. Anchorage relaxation caused by large deformation and creep of the soft historical masonry can reverse the effect of prestressing [11,12].

Second, surface preparation is restricted, or even prohibited, when strengthening the historical masonry walls. Because the historical masonry substrate is vulnerable and sensitive. Under the circumstance, the bondage of the strengthening layers or strips is difficult to guarantee. In addition, unfavorable stress concentrations can take place within masonry substrates, the externally bonded layers or strips, and their interfaces. If the strengthening layers or strips are made of FRP with anisotropic and brittle nature, the stress concentration can result in piercing or threading effects on them [13].

Third, it is difficult to achieve favorable integrity of the strengthened historical masonry walls, if the walls have been damaged significantly before strengthening. When applying strengthening layers on these walls, the integrity of the damaged substrates and the layers are unreliable because it is subject to many uncertain factors. For example, the walls' aspect ratio, the damage distribution and extent, the properties of the bricks and mortar, the properties of the strengthening materials, and so on [14-17]. When applying strengthening strips on these walls, the integrity of the strengthened walls may relate to the strip configuration [18]. For example, damaged parts of the walls that are not covered by the strengthening strips can undergo large deformation under high stress, and result in collapse of the walls potentially [14].

Besides, an important requirement for strengthening historical masonry walls is the reversibility of the intervention [19-21], which keeps the possibility to remove and replace the retrofit when the advances in technology will allow better strategies.

Considering the characteristics of the historical masonry walls, to cover their surfaces entirely using strengthening layers is preferable. The materials used to construct the strengthening layers should deform well with the soft masonry substrates, have favorable strength, and have good ductility. The ultra-high performance concrete (UHPC) is a potential candidate because of its favorable features [22]. First, the ductility of the UHPC is much better than that of the historical masonry, and the favorable ductility helps to bring in good energy dissipation ability of the strengthened walls. Second, the tensile strength, the compressive strength, and the shear strength of the UHPC are much higher than those of the historical masonry respectively, and the higher strength ensures the strengthening effect under different stress states. Third, the UHPC has no coarse aggregate and then has good grouting ability. This feature has been verified by its successful applications in grouting the rebar-splicing couplers in prefabricated concrete members [23]. With the good grouting ability, the UHPC can flow into and fill the existing damages in the masonry substrates before hardening. Such a mechanism makes the UHPC deform well with the masonry substrates, and it relieves influence of the seasonal difference between the thermal strain of the UHPC layers and the masonry substrates.

Although the UHPC layers are not completely removable after being applied, their thickness can be very small because they do not require reinforcement inside. When the advances in technology allow better strategies, they can be applied on top of the thin UHPC layers without changing the profile of the masonry walls. From this angle, the UHPC layers allow the realization of better strategies like those reversible retrofitting strategies do. 
The research about the strengthening effect of applying UHPC layers on historical masonry walls is not enough yet. To contribute to the field, the authors conduct pseudo-static experiments on historical squat masonry walls strengthened by UPPC layers and reinforced polymer mortar layer, and they compare the strengthening effect of the two kinds of layers. The structure of the paper is as follows. In Section 2, the authors present a detailed experimental scheme with special considerations on characteristics of the historical brick masonry walls. In Section 3, they present and compare the experimental results in terms of failure mode, in-plane shear resistance, stiffness degradation, and ductility of the walls. These results reflect the static and seismic performance of the walls quantitatively. In Section 4, the authors evaluate the strengthening effect of applying the UHPC layers, with emphasis on the favorable interaction between the UHPC and the masonry substrates. Finally, they summarize the research findings in Section 5.

\section{Experimental Scheme}

\subsection{Preparation of the Historical Masonry}

The above-mentioned characteristics of historical brick masonry walls influence the effect of the strengthening methods significantly. To simulate the historical brick masonry walls under strengthening authentically, the bricks used in this research were collected from a real historical building under rehabilitation, as shown in Figure 1a. The six-story building was constructed in 1929 and it has a mixed structure that consisted of concrete frames, masonry walls, and concrete floors. The height of story 1 to story 6 are $4.877 \mathrm{~m}, 3.353 \mathrm{~m}, 3.353 \mathrm{~m}, 3.353 \mathrm{~m}, 3.000 \mathrm{~m}$, and $3.000 \mathrm{~m}$, respectively. The plan of each story is close to a rectangular whose dimension is $17.2 \mathrm{~m} \times 32.7 \mathrm{~m}$. The bricks used in this research were collected from the masonry walls in story 5 . The historical bricks had damages and their shape was irregular, as shown in Figure 1b. They helped to reproduce the rough brick-mortar interface within the historical walls. The authors measured the strength of the historical bricks by conducting compressive tests of 10 random samples. It found that the average compressive strength was $6.2 \mathrm{~N} / \mathrm{mm}^{2}$ and the standard deviation was $0.5 \mathrm{~N} / \mathrm{mm}^{2}$.

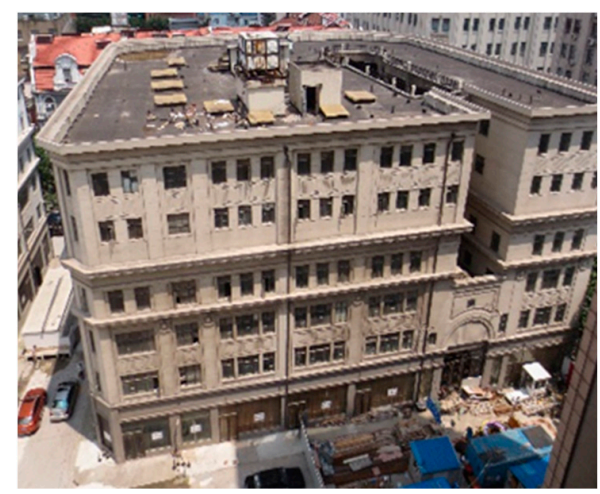

(a)

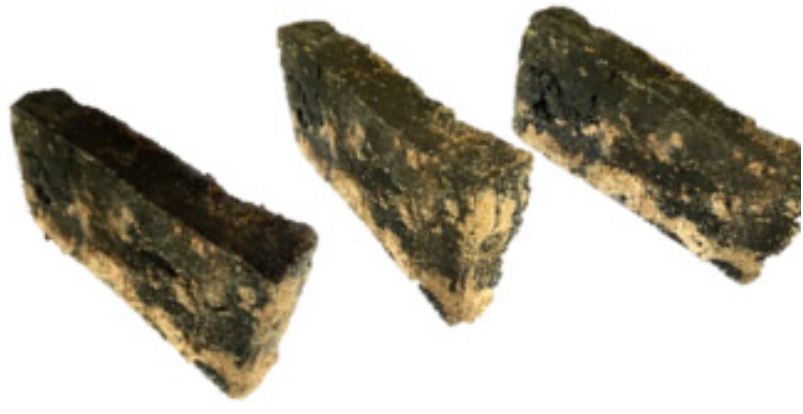

(b)

Figure 1. The historical building and bricks: (a) The historical building under rehabilitation; (b) the bricks sampled from the historical building.

The mortar used to construct the bed and head joints had a special mixture that ensured the low strength. The mixture contained no Portland cement, but it contained meshed powder of mortar beds collected from the same historical building. Such a mixture simulated the ingredients of the historical mortar, and then helped to reproduce the bonding between bricks and mortar in the historical walls. The weight ratio of water, lime, and sand in the mortar was 1:1:6. The authors measured the strength of the mortar by conducting compressive tests on six cubic mortar specimens. The specimens were sampled from the batch that would be used to construct the walls. It found that the average compressive strength was $0.4 \mathrm{~N} / \mathrm{mm}^{2}$ and the standard deviation was $0.13 \mathrm{~N} / \mathrm{mm}^{2}$. 
Three masonry prisms whose size were $240 \mathrm{~mm} \times 365 \mathrm{~mm} \times 766 \mathrm{~mm}$ were constructed and cured simultaneously with the walls. The authors measured the masonry strength by conducting compressive tests on the prisms. It found that the average compressive strength was $0.74 \mathrm{~N} / \mathrm{mm}^{2}$ and the standard deviation was $0.11 \mathrm{~N} / \mathrm{mm}^{2}$.

\subsection{Mechanical Properties of the Strengthening Materials}

Two kinds of layer were used to strengthen the walls, i.e., the UHPC layer and the reinforced polymer mortar layer. The latter was constructed by coating a grid of steel bars with polymer mortar. The UHPC was mixed by water, cement, superfine cement, sand, scoria, high-performance water reducer, and fine steel fiber with a weight ratio of 1:2.32:1.14:5.30:2.34:0.11:0.59. The polymer mortar was mixed by water, cement, sand, and additive with a weight ratio of 1: 3.33: 6.67: 0.6. The reinforced steel bars were of class HPB235 in the Chinese code GB 50010-2010 and their sectional diameter was $6 \mathrm{~mm}$. Mechanical properties of the strengthening materials are shown in Table 1.

Table 1. Mechanical properties of the strengthening materials. UPHC: ultra-high performance concrete.

\begin{tabular}{|c|c|c|c|c|c|}
\hline Material & $\begin{array}{c}\text { Compressive } \\
\text { Strength } \\
\left(\mathrm{N} / \mathrm{mm}^{2}\right)\end{array}$ & $\begin{array}{c}\text { Tensile } \\
\text { Strength } \\
\left(\mathrm{N} / \mathrm{mm}^{2}\right)\end{array}$ & $\begin{array}{c}\text { Elastic } \\
\text { Mmodulus } \\
\left(\times 10^{5} \mathrm{~N} / \mathrm{mm}^{2}\right)\end{array}$ & $\begin{array}{c}\text { Strain at } \\
\text { Elastic Limit } \\
\quad(\mu \varepsilon)\end{array}$ & $\begin{array}{c}\text { Ultimate } \\
\text { Tensile Strain } \\
\quad(\mu \varepsilon)\end{array}$ \\
\hline UHPC & 137.60 & 5.80 & 0.49 & 200 & 1100 \\
\hline Polymer mortar & 19.10 & 3.10 & 0.30 & - & - \\
\hline Reinforcing bar & 345.00 & 345.00 & 2.10 & 1700 & 110000 \\
\hline
\end{tabular}

The elastic modulus and the thermal expansion coefficient of the UHPC are far different from that of masonry. Therefore, the seasonal variation of thermic strain of the UHPC will be different from that of the masonry substrate. The strain difference would provoke unfavorable stress in the masonry, but the interaction between the UHPC and the masonry substrates would relieve the stress, as explained in Section 4.2.

\subsection{Construction of the Squat Masonry Walls}

Three squat walls were constructed using the above-mentioned materials and labeled by W1, W2, and W3 respectively. The W1 was constructed without any strengthening measure, the W2 was constructed and strengthened by a UHPC layer, and the W3 was constructed and strengthened by a reinforced polymer mortar layer. The authors applied in-plane lateral load cyclically on W1 under constant vertical compression until the wall failed, and then strengthened the failed W1 in-situ with a UHPC layer. The strengthened wall was labeled as W1S, and it was loaded to failure again.

To limit the variety of structural details, two senior technicians constructed the masonry walls in three consecutive days and then cured the bare walls for two weeks. After curing the walls, the strengthening was finished in three consecutive days. On day 1, the mixing of the UHPC and strengthening with the UHPC layer was completed. On day 2, the grid of steel bars was formed. On day 3 , strengthening with the reinforced polymer mortar layer was completed. After the strengthening and before the tests, the authors cured the strengthened walls for 28 days in a stable lab environment. The curing temperature was between $17^{\circ} \mathrm{C}$ and $23^{\circ} \mathrm{C}$, and the environmental humidity was greater than $90 \%$.

The profile of the walls is shown in Figure 2. Thickness of the walls was $240 \mathrm{~mm}$ and thickness of the mortar joints was $10 \mathrm{~mm}$, like those measured in the historical building. Thickness of the UHPC layers on W2 and W1S was $40 \mathrm{~mm}$, like that of the general strengthening layers used in practices (in China). The UHPC layers are thinner than other strengthening layers that work with inner reinforcement. Therefore, it is possible to apply extra strengthening measures on top of the UHPC layers without changing the profile of the historical walls. The authors controlled the thickness of the UHPC layers using a wooden mold, as shown in Figure 3a. They injected the UHPC batch from a 
hole on the bottom of the mold, until the space between the mold and the wall surfaces was filled. During the procedure, the UHPC batch also immersed and filled the existing damages in the walls. Such a strengthening procedure had slight intervention on the damaged masonry walls, as required by most rehabilitation practices. Moreover, it potentially helped to improve the integrity of the masonry substrates, the elastic modulus of the target walls, and the bondage between the UHPC layers and the masonry substrates.

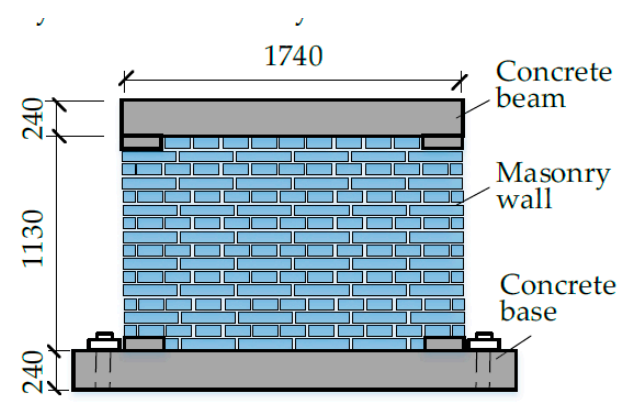

(a)

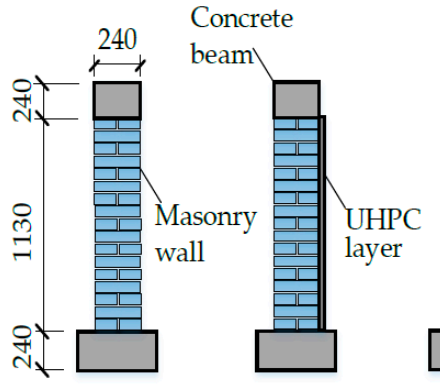

(c)

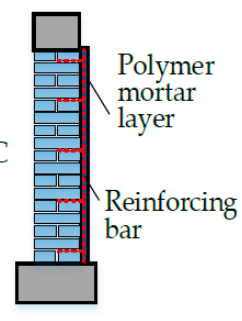

(d)

Figure 2. Profile of the historical wall specimens: (a) Front view; (b) right view of W1; (c) right view of W2 and W1S; (d) right view of W3.

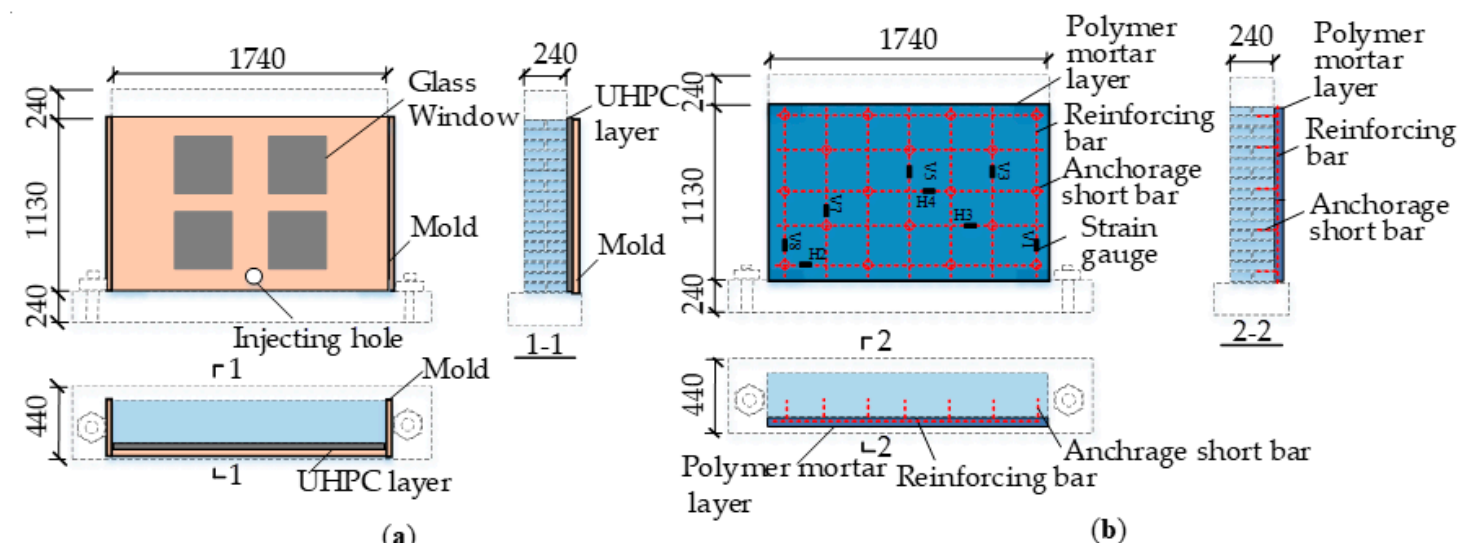

(a)

(b)

Figure 3. Construction of the strengthening layers: (a) The UHPClayer; (b) The reinforced polymer mortar layer.

Comparatively, strengthening with the reinforced polymer mortar layer was more complicated. First, the surface of the masonry substrate was cleared, and then anchoring short reinforcing bars were planted into the masonry, as shown in Figure 3b. As the following step, the reinforced grid was hung on the anchoring short bars and then was fasten by binding. The polymer mortar was then spread onto the cleared surface of the masonry substrate by two times. After the first time, the polymer mortar layer was just thick enough to cover the reinforced grid; after the second time, the polymer mortar layer reached its design thickness of $50 \mathrm{~mm}$. Planting of anchoring short bars and spreading of polymer mortar had obvious intervention on the target wall. These measurements can be inapplicable if the masonry substrate had been damaged severely, as the case of W1S. In addition, the polymer mortar layer had a minimum thickness to coat the reinforced grid effectively. Such a minimum thickness is not always applicable for rehabilitation of historical buildings.

It should be noted that the aspect ratio has significant influence on the performance of masonry walls. However, the amount of the collected historical bricks and mortar was limited and not enough to construct more specimens with different aspect ratios. Therefore, the authors focused on the squat walls that is a typical class of members in historical structures. The in-plane shear failure of the squat walls is brittle and the strengthening effect of the squat walls could be more convincing. 
By comparing the experimental results of $\mathrm{W} 1, \mathrm{~W} 2$, and W1S, strengthening effect of the UHPC layer for masonry walls with different damage extent can be evaluated. By comparing the experimental results of $\mathrm{W} 1$ and $\mathrm{W} 3$, strengthening effect of the reinforced polymer mortar layer can be evaluated. By comparing the experimental results of $\mathrm{W} 1, \mathrm{~W} 2$, and $\mathrm{W} 3$, the difference in the strengthening effect of the UHPC layer and the reinforced polymer mortar layer can be evaluated.

\subsection{Test Setup and Loading Mechanism}

The test setup and transducer layout are shown in Figure 4. The displacement transducers were used to measure deformation of the walls, and their records were used to evaluate the walls' failure modes. The strain gauges $\mathrm{C} 1, \mathrm{C} 2$, and $\mathrm{C} 3$ on the strengthening layers, along with those on the reinforcing bars and shown in Figure 3b, were used to evaluate the strain distribution within the walls and to evaluate the deformation of the strengthening layers.

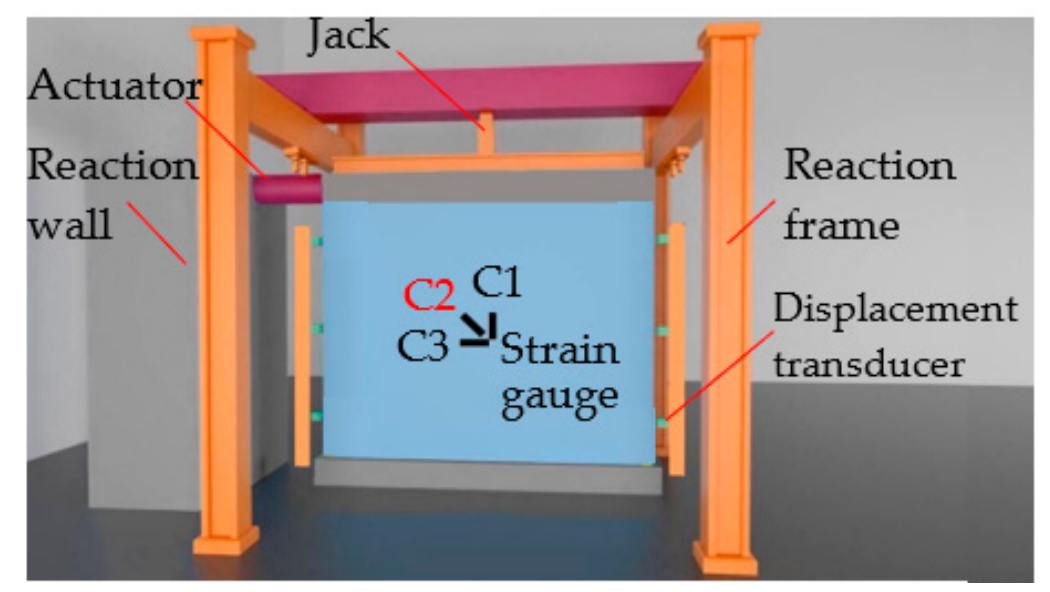

Figure 4. Test setup.

The loading mechanism was same for all the walls. Vertical compression was firstly applied by a jack and then remained unchanged, resulting in a constant compressive ratio of 0.3 on the wall being tested. The compressive ratio is typical of the bottom walls of regular two-story masonry buildings (in China). After vertical loading, cyclical lateral forces were applied along the top concrete beam by a servo-hydraulic actuator. The lateral loading stopped if the force of the actuator dropped by $15 \%$ or more, as illustrated in Figure 5.

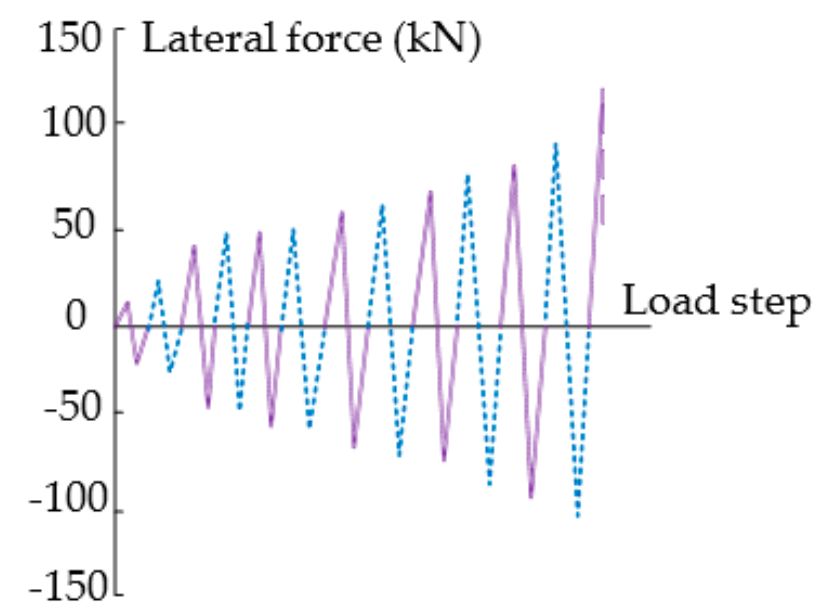

Figure 5. Lateral load cycles. 


\section{Experimental Results}

\subsection{Deformation and Failure Mode}

There were three typical states of the walls during they deformed under the lateral loading. At state 1, major cracks in the walls became visible; at state 2, lateral forces on the walls reached their peak values; and at state 3 , the forces of the actuator dropped by $15 \%$ or more after reaching peak values and the walls failed. The lateral displacement of the walls along their height at the three typical states is shown in Figure 6, in which $\Delta$ represents the displacement.

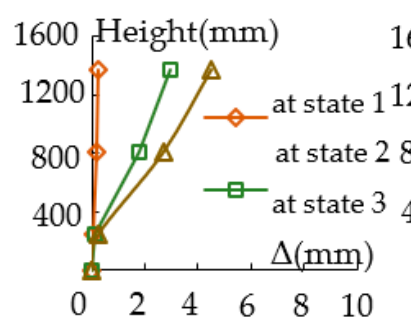

(a)

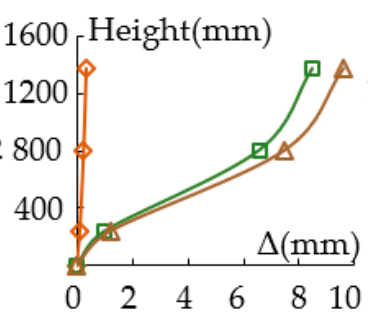

(b)

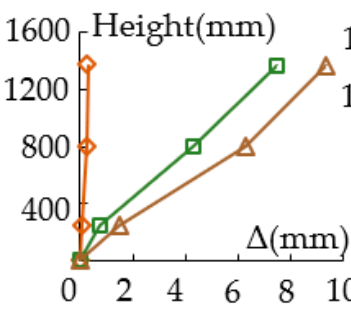

(c)

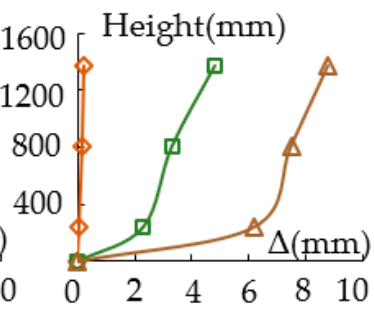

(d)

Figure 6. Lateral displacement of the walls: (a) W1; (b) W1S; (c) W2; (d) W3.

The displacement of the lower part of the W1 remained small until the wall failed, while the displacement of the lower parts of all the strengthened walls increased obviously with the load.

The W1 and W1S deformed similarly at state 1, indicating the UHPC layer had recovered the stiffness of the failed W1. However, the displacement of W1S at state 2 and state 3 is much larger than that of W1, indicating the UHPC layer had postponed the cracking and changed the failure mode. Because of the favorable cooperation between the UHPC layer and the masonry substrate, the ultimate deformation of W1S-which was recovered from the severely damaged W1-increased by $113 \%$ than that of W1. Similar result was observed for W2, whose ultimate deformation increased by $109 \%$ than that of W1. The difference between the increase of the ultimate deformation of W1S and W2 was less than $4 \%$, indicating the improvement of ultimate deformation was similar for the two walls. The similarity can be explained by the walls' failure mode. Both W1S and W2 failed in a bed-joint slide mode that was premature and the strengthening layers had not taken full effect. Therefore, the ultimate deformation of W1S and W2 relied much on the resistance of the masonry in their bottom, as explained in Section 4.3. The resistance of the bottom masonry is similar for W1S and W2, because the W1 had previously failed in a typical shear-compressive mode and its bottom masonry was still in good condition after the failure. The results indicate the UHPC layers significantly improved the deformation ability of the masonry walls.

While, the ultimate deformation of W3 increased by $96 \%$ than that of W1. The increase is less than that of W1S and W2 because the UPCP layers deformed with the masonry substrates better than the reinforced polymer layer did, as explained in Section 4.2 and Figure 14. Besides, the W3 had a large displacement at the bottom when it failed, indicating a severe bed-joint slide.

There were two failure modes of the walls, as shown in Figure 7. The unstrengthened W1 failed in a typical shear-compressive mode, like most load-bearing walls with weak mortar joints. Cracks originated when the lateral force was only $18 \mathrm{kN}$, and crossing cracks formed when the lateral force was only $35 \mathrm{kN}$. In the subsequent load cycles, lateral deformation of the wall increased significantly. It failed suddenly when the lateral force was $41.4 \mathrm{kN}$, and then the force of the actuator dropped. 

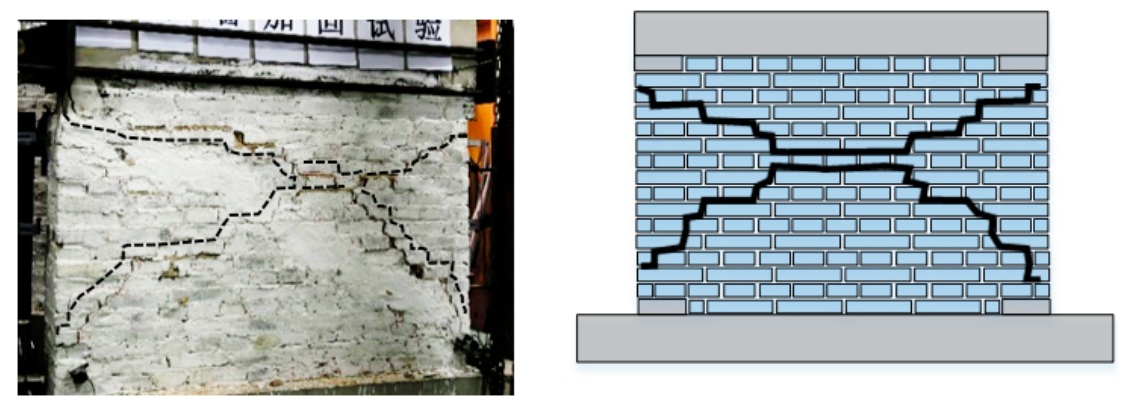

(a)
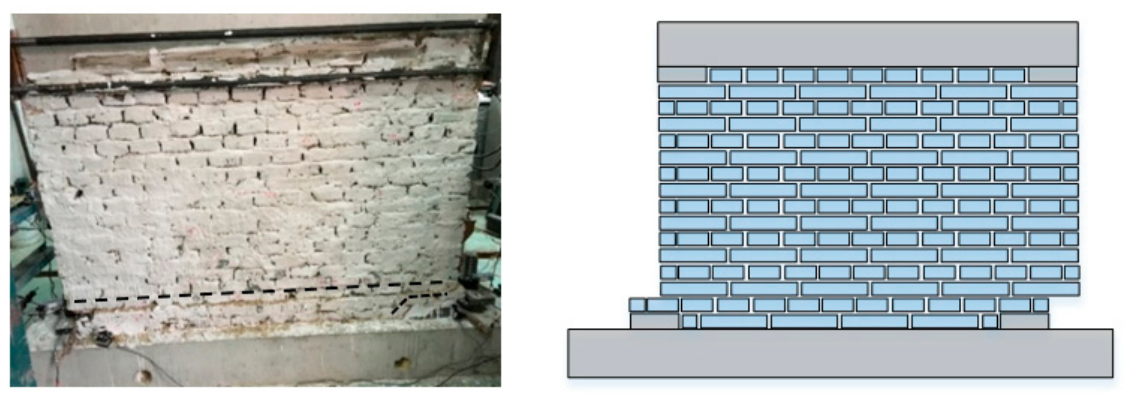

(b)

Figure 7. Failure modes of the walls: (a) Shear-compressive failure of the unstrengthened W1; (b) bed-joint slide of the strengthened walls.

For the strengthened walls W1S, W2, and W3, horizontal cracks formed and developed at their bottom along with the increase of the lateral forces, and the walls failed through bed-joint slide finally. The horizontal cracks of the W1S, W2, and W3 formed at their bottom when the lateral forces were $32.4 \mathrm{kN}, 40.8 \mathrm{kN}$, and $31.0 \mathrm{kN}$ respectively, which were much higher than that of the cracking load of W1. No severe cracks formed in other parts of the walls after the horizontal cracking, until the walls failed through bed-joint slide suddenly. Such a failure mode of strengthened historical masonry walls hardly happens for strengthened regular masonry walls, for which debonding of the externally bonded layers or strips is the typical failure mode.

\subsection{In-Plane Shear Resistance}

The skeleton curves the walls are illustrated in Figure 8. The in-plane shear resistance of W1 was low because the historical bricks and mortar were weak. Moreover, irregular shapes of the historical bricks resulted in complicated interactions between the bricks and the surrounding mortar. Failure was more prompt to happen under the combined effect of shear stress, compressive stress, and extra stress introduced by the strain difference between the bricks and the mortar. The wall cracked and crushed severely and lost integrity when it failed. Although it was crushed and split into several parts, the UHPC layer effectively rehabilitated it. The in-plane shear resistance of W1S, which was constructed by strengthening the crushed W1, was 147\% higher than that of W1.

The W2 was strengthened by the UHPC layer before loading, and it had the highest in-plane shear resistance within all the walls. Its resistance was 193\% higher than that of W1. It shows that the applied UHPC layer also improved the resistance of the masonry wall that has visible but not severe damages.

The W3 was strengthened by the reinforced polymer mortar layer before loading. Its in-plane shear resistance increased less than that of W2 and W1S. 

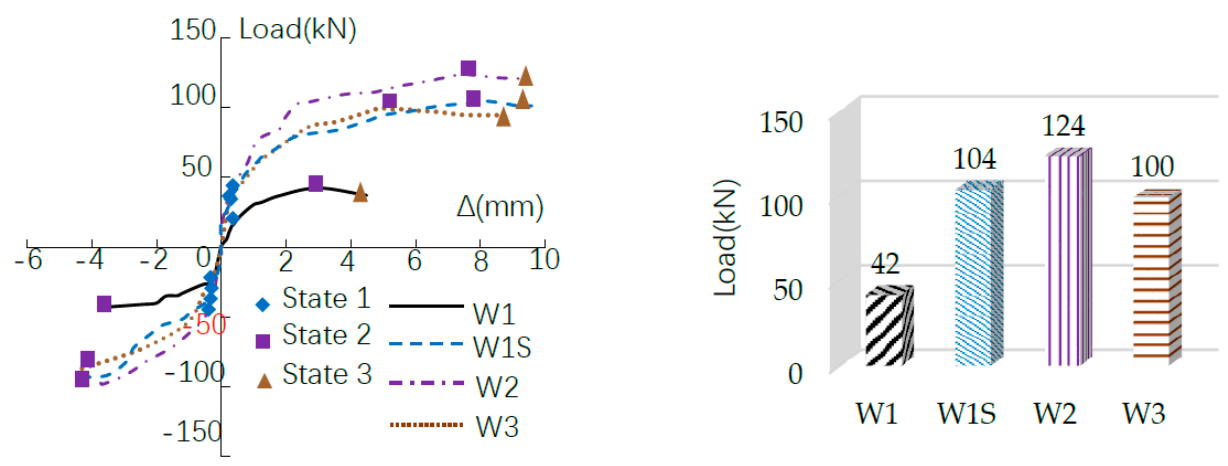

Figure 8. In-plane shear resistance of the walls: (a) Skeleton curves; (b) resistance.

\subsection{Stiffness Degradation}

Secant stiffness of the walls in each load cycle can be calculated as follows,

$$
K_{i}^{+}=\frac{V_{i}^{+}}{\Delta_{i}^{+}}, \quad K_{i}^{-}=\frac{V_{i}^{-}}{\Delta_{i}^{-}}
$$

where, $K_{i}^{+}$and $K_{i}^{-}$are the secant stiffness during positive and negative loading in the $i$ th cycle, respectively; $V_{i}^{+}$and $V_{i}^{-}$are the maximum lateral forces during positive and negative loading in the $i$ th cycle, respectively; and $\Delta_{i}^{+}$and $\Delta_{i}^{-}$are the deformation corresponding to the maximum lateral forces.

The secant stiffness of the walls decreased at different pace along with the increase of lateral forces, as shown in Figure 9. The secant stiffness dropped dramatically before state 1, indicating the existing damages in the bricks, the mortar, and the brick-mortar interface were very sensitive and could develop significantly under very small lateral forces. After dropping to a low level at state 1 , the secant stiffness degraded gradually.

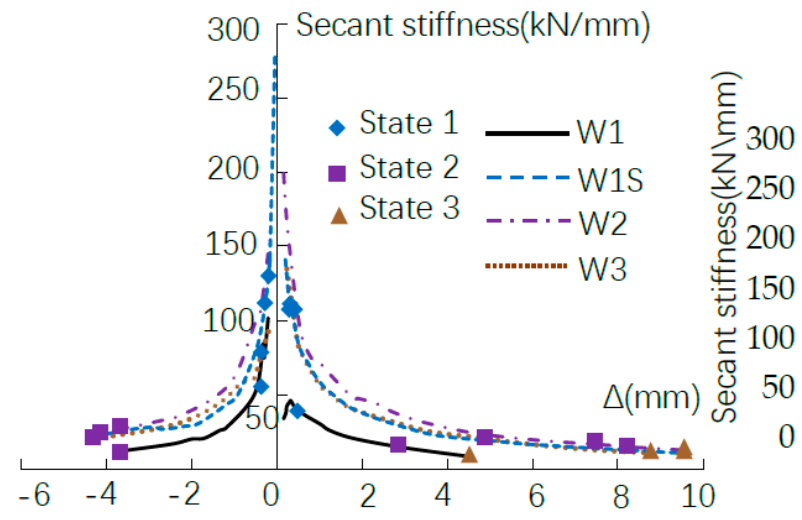

(a)

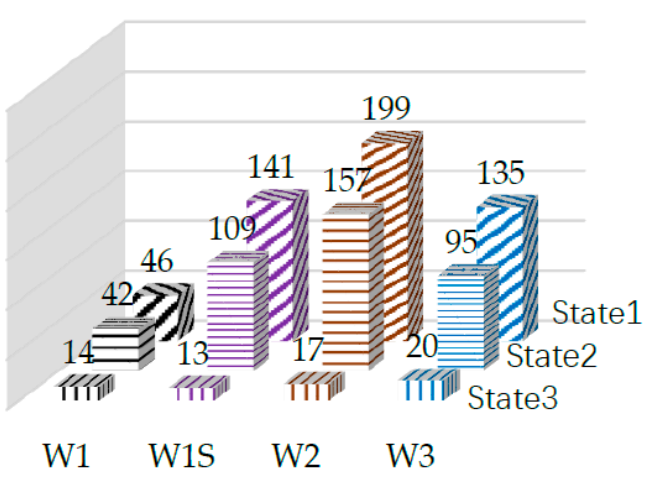

(b)

Figure 9. Stiffness degradation: (a) Stiffness degradation during the loading procedures; (b) stiffness at typical states.

The strengthened walls retained their stiffness in a rather long deformation procedure before they failed, indicating the UHPC layers and the reinforced polymer mortar layer took obvious effect after state 1 and the walls' integrity was rehabilitated.

\subsection{Ductility and Energy Dissipation}

The ultimate deformation of the strengthened W1S, W2, and W3 was $113 \%, 109 \%$, and $96 \%$ higher than that of the unstrengthened W1, and the area of the hysteretic loops of the strengthened W1S, W2, and $\mathrm{W} 3$ was $68 \%, 120 \%$, and $50 \%$ higher than that of the unstrengthened W1, as shown in Figure 10 . 
The results indicate that the strengthened walls dissipated more energy before failure. The UHPC layers improved the energy dissipation ability of the masonry walls, whether the wall was in good condition as the W2 or had been severely damaged as the failed W1.

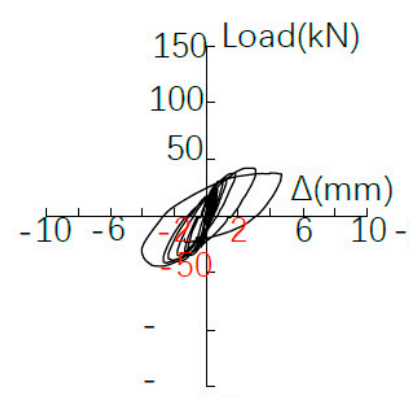

(a)

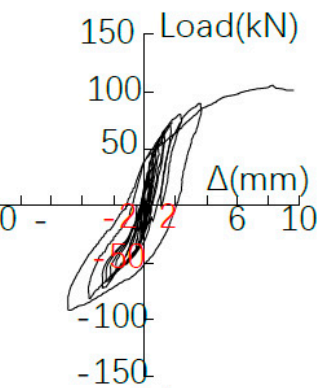

(b)

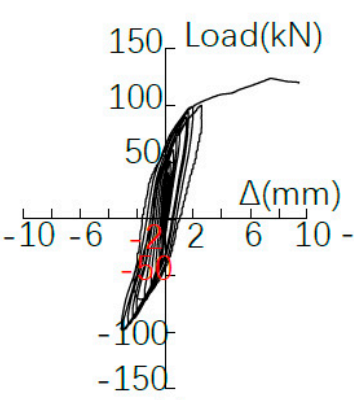

(c)

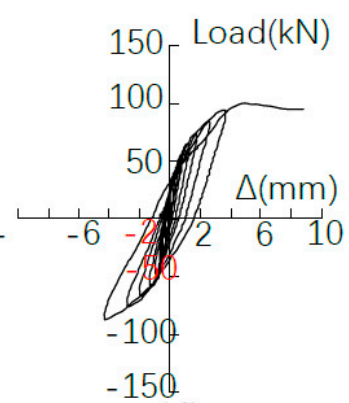

(d)

Figure 10. Hysteretic loops of the walls: (a) W1; (b) W1S; (c) W2; (d) W3.

Although the hysteretic loops of the strengthened walls surrounded more area, they were not plump. Therefore, the increase of energy dissipation mainly resulted from the increase of resistance, and the strengthened walls' energy dissipation ability was not as favorable as their in-plane shear resistance. This can be illustrated by Figure 11, in which the energy dissipation coefficient equals the area of the shaded part ABCD divided by the sum of the area of the triangle OBE and triangle ODF. The enhancement of energy dissipation had been reversed by the premature bed-joint slide failure, in which the strengthening layers had not taken effect sufficiently.

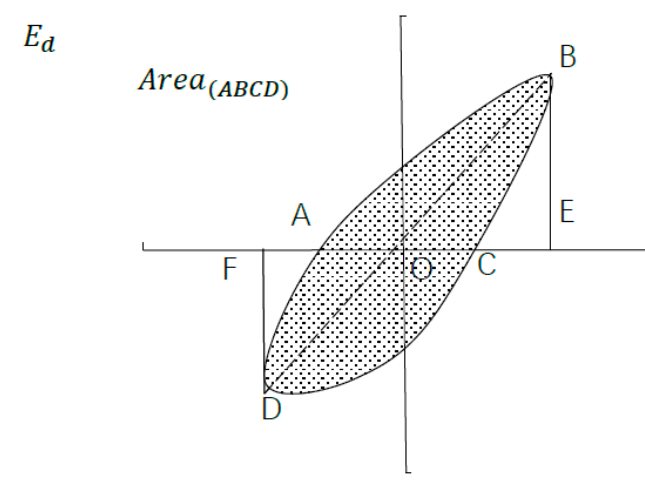

(a)

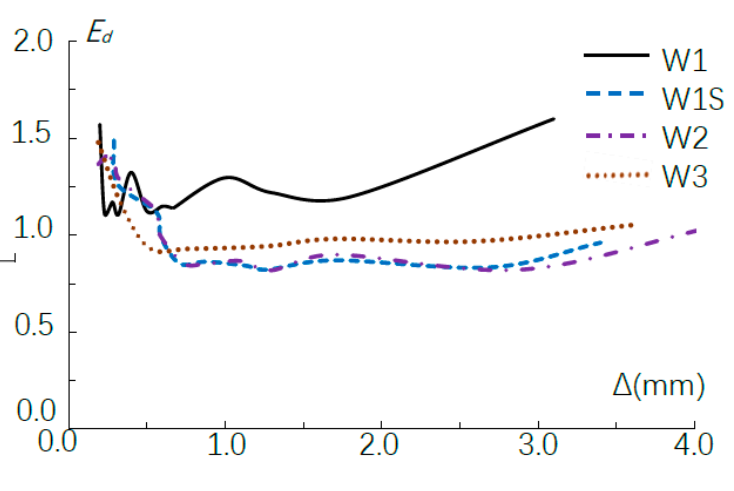

(b)

Figure 11. Energy dissipation coefficients $\left(E_{d}\right)$ of the walls: (a) Calculation of the energy dissipation coefficient; (b) energy dissipation coefficients of the walls.

\section{Performance Analysis of the Strengthened Walls}

\subsection{Strengthening Effect}

The strengthening layers simultaneously improved the resistance, ultimate deformation, ductility, and energy dissipation ability of the masonry walls, as shown in Figure 12. They also improved the stiffness of the walls, indicating an obvious effect of integrity rehabilitation. However, from a seismic point of view an increment of stiffness is generally associated to an increment of the spectral acceleration, that is an increment on the force acting on the structure in seismic conditions. Therefore, an increment in the stiffness of the panel cannot be considered good for the structure and the benefit in terms of increment of resistance could partially or totally vanish because of the higher stiffness. 


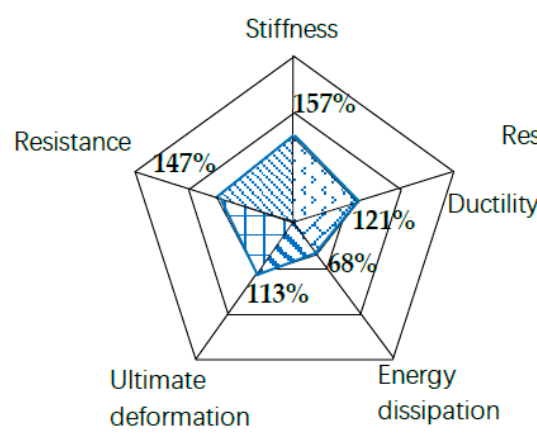

(a)

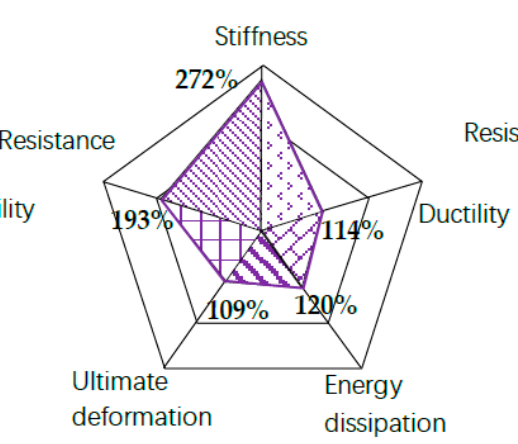

(b)

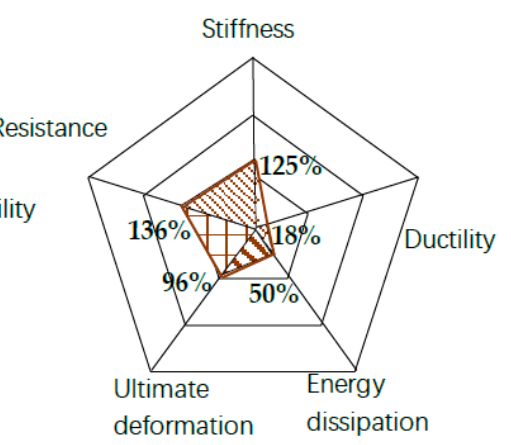

(c)

Figure 12. Percentage of performance rehabilitation and improvement of the strengthened walls comparing to the unstrengthened W1: (a) W1S; (b) W2; (c) W3.

The UHPC layers had better strengthening effect than the reinforced polymer mortar layer, because they had more favorable interaction with the masonry substrate as explained in Section 4.2. Besides, the UHPC layer has three advantages. First, it had favorable strengthening effect for both W1S and W2, although the former had severe damages as shown in Figure 7a before being strengthened. For such a severely damaged wall, the reinforced polymer mortar layer is very difficult, if not impossible, to apply. Second, the construction of the UHPC layer had very slight architectural and structural intervention on the target walls. Therefore, the UHPC layer is more appropriate for strengthening historical walls under different load cases. Third, the UPHC layers will not prevent the realization of better strengthening strategies in the future. The UHPC layers are thin because they do not require reinforcement inside. Other strengthening strategies can be applied on top of the thin UHPC layers, without changing the profile of the historical walls.

\subsection{Interaction between the Strengthening Layers and the Masonry Substrate}

To investigate the interaction between the UHPC layers and the masonry substrate, cylinder core samples were drilled out of the failed W1S and W2, as shown in Figure 13. It shows the UHPC had flowed into and filled the existing damages in the masonry substrate, and it had rehabilitated the masonry substrate before strengthening the walls. The mechanism not only prevented the development of the damages that had existed in the target walls before strengthening, but also improved the bondage between the UHPC layers and the masonry substrate. Moreover, it would relieve the unfavorable stress provoked by the thermal strain difference between the UHPC layers and the masonry substrate.

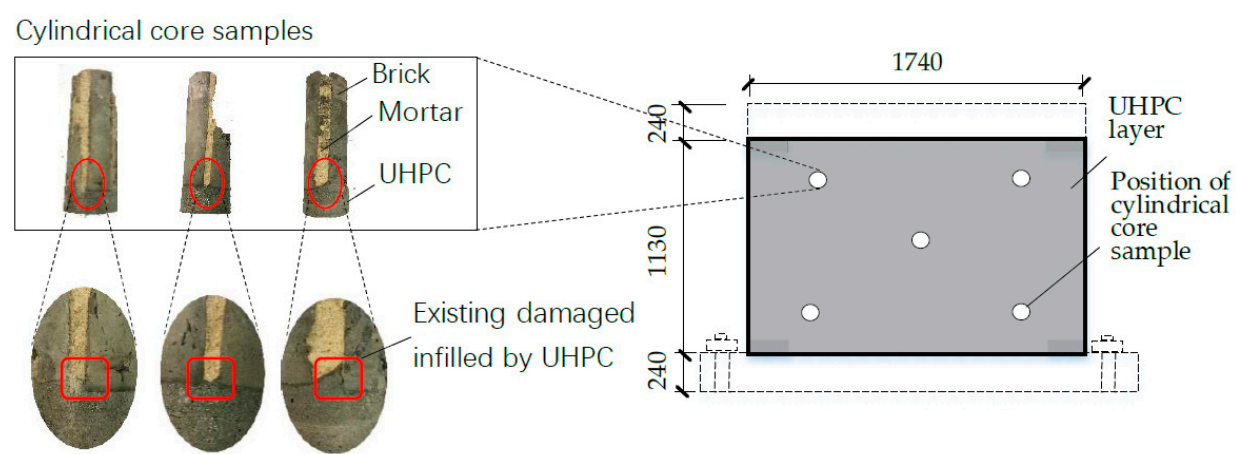

Figure 13. Interaction mechanism between the UHPC layer and the masonry substrate. 
The mechanism that results in the favorable strengthening effect has minor relation to the walls aspect ratio. Therefore, similar strengthening effect could be expected when the UHPC layers are applied on slender masonry walls. It should be noticed that the UHPC layers could change the ratio of the bending stiffness to the shearing stiffness of the slender walls, and then change the walls' ductility or failure mode. The reinforced polymer mortar layer did not have the above-mentioned mechanism. The interface between the layer and the masonry substrate was much smoother than that between the UHPC layer and the masonry substrate, as shown in Figure 14. The reinforced polymer mortar layer ensured the bondage with the masonry substrate by cohesion and dowel action from the anchorage short bars illustrated in Figure 3b. As a result, it was less effective than the UHPC layers.

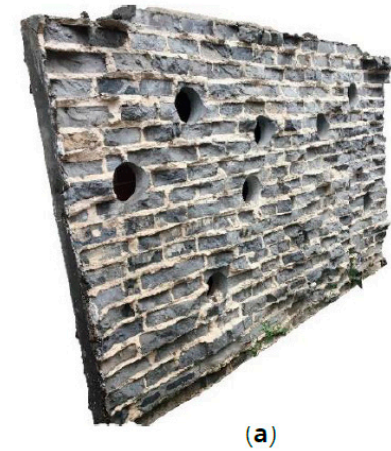

(a)

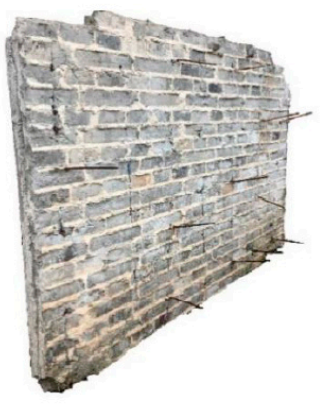

(b)

Figure 14. The interface between the strengthening layers and the masonry substrate: (a) The coarse interface between the UHPC layer and the masonry substrate; (b) The smooth interface between the reinforced polymer mortar layer and the masonry substrate.

\subsection{Failure by Bed-Joint Slide}

The failure by bed-joint slide of the strengthened masonry walls is different from the typical shear-compressive failure. The UHPC layers and the reinforced polymer mortar layer strengthened the masonry significantly, but they did not cover the bottom parts of the walls effectively. Meanwhile, the bottom parts of the walls resisted the maximum shear forces and moments. Therefore, the bottom parts became the weakest and the failure by bed-joint slide was triggered.

During the procedure of the bed-joint slide, the strain of the reinforcing bars at the bottom of the W3 was larger than that of the reinforcing bars in other parts, as shown in Figure 15a. Figure 15 also shows the strain of all the reinforcing bars and the UHPC was far less than their ultimate strain during the procedure. Therefore, the strengthening layers had not taken full effect and the failure by bed-joint slide was premature.
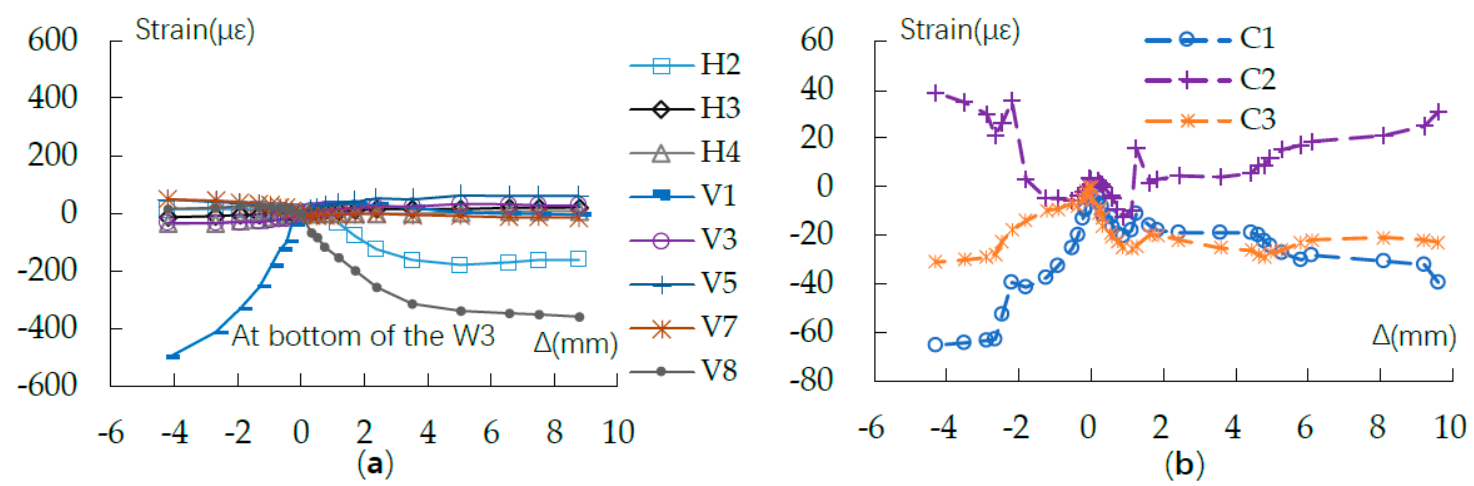

Figure 15. Strain of the strengthening layers: (a) Strain of the reinforcing bars of W3, the gauge position is illustrated in Figure 3b; (b) Strain of the UHPC of W2, the gauge position is illustrated in Figure 4. 
The bed-joint slide is more prompt for squat walls for which the in-plane shear deformation is dominant. For the slender walls, there is significant compressive stress caused by the in-plane bending deformation and normal to the bed-joints. The compressive stress is favorable for preventing the premature bed-joint slide. Therefore, better energy dissipation ability could be expected when the UHPC layers are applied on slender masonry walls.

To prevent such a premature failure mode, strengthening scheme should be designed at structural level: the joints among adjacent strengthened walls, like the bottoms of the W1S, W2, and W3, should be strengthened simultaneously. Such a scheme can strengthen the walls more effectively. More importantly, it can improve the seismic performance of the entire structure because it improves the structural integrity.

\section{Conclusions}

The strengthening effect of applying UHPC layers and reinforced polymer mortar layer on historical squat masonry walls is investigated through pseudo-static experiments. The experimental results highlight the strengthening effect of the UHPC layers, but indicate the premature failure by bed-joint slide of the strengthened walls. The conclusions as follows can be drawn,

1. The UHPC layer improved a typical historical squat wall's resistance by $193 \%$, cracking load by $127 \%$, and ultimate deformation by $109 \%$ simultaneously. The increase of resistance is favorable for ensuring the safety of the historical walls under static load, the increase of cracking load is favorable for ensuring the serviceability, and the increase of ultimate deformation is favorable for ensuring the safety of the historical squat walls under seismic load. The UHPC layer also increased the stiffness of the wall, indicating an obvious effect of integrity rehabilitation. Its strengthening effect was more obvious than that of the reinforced polymer mortar layer. Therefore, the UHPC layer is appropriate for both static and seismic strengthening of historical squat masonry walls, and it is favorable for restoring the serviceability of the walls.

2. The UHPC layer rehabilitated a severely damaged historical squat wall and improved its resistance by $147 \%$ and ultimate deformation by $113 \%$ simultaneously. It also increased the stiffness of the wall, indicating an obvious effect of integrity rehabilitation. The UHPC can fill the existing damages in the wall. Such a mechanism rehabilitated the masonry substrate before strengthening, and made the UHPC deformed with the masonry well. The mechanism is specifically favorable for strengthening historical masonry walls that have been severely damaged. Because the mechanism has minor relation to the walls' aspect ratio, similar strengthening effect could be expected when the UHPC layers are applied on slender masonry walls.

3. The historical squat masonry walls strengthened by the UHPC layers failed through bed-joint slide at their bottom, and their energy dissipation ability was not excellent. The bed-joint slide was governed by the strength of the weak bottom parts of the walls. These parts resisted the maximum shear forces and bending moments, but they were not effectively covered by the strengthening layers. For the slender walls, there is significant compressive stress caused by the in-plane bending deformation and normal to the bed-joints. The tendency to bed-joint slide could be relieved.

4. The premature failure by bed-joint slide of individual strengthened walls should be prevented in the strengthening of historical structures. Therefore, the strengthening scheme should be designed at structural level. The interactions among adjacent walls should be well considered, and the joints among the strengthened walls should be strengthened simultaneously.

The UHPC layers are easy to apply and they have slight intervention on the vulnerable historical masonry walls, and they will not prevent the realization of better strengthening strategies in the future. With appropriate strengthening scheme, the UPHC layers are potentially effective and efficient for strengthening the historical squat masonry walls. 
Author Contributions: Conceptualization, B.P.; methodology, L.L.; validation, S.W.; formal analysis, S.W.; investigation, L.L.; resources, Q.Z.; writing—original draft preparation, L.C.; writing-review, editing, and revising, B.P.; visualization, Y.M.; supervision, B.P. and Q.Z.; project administration, Y.M.; funding acquisition, B.P. and Q.Z.

Funding: This research was founded by the National Natural Science Foundation of China (NNSFC), grant numbers 51208300

Conflicts of Interest: The authors declare no conflicts of interest.

\section{References}

1. Triantafillou, T.C.; Fardis, M.N. Strengthening of historic masonry structures with composite materials. Mater. Struct. 1997, 30, 486-496. [CrossRef]

2. Edwards, J. Cracking in historic masonry and surface finishes: conservation approaches and solutions. J. Build. Apprais. 2004, 1, 20-33. [CrossRef]

3. Valluzzi, M.R.; Binda, L.; Modena, C. Mechanical behaviour of historic masonry structures strengthened by bed joints structural repointing. Constr. Build. Mater. 2005, 19, 63-73. [CrossRef]

4. Capozucca, R. Experimental analysis of historic masonry walls reinforced by CFRP under in-plane cyclic loading. Compos. Struct. 2011, 94, 277-289. [CrossRef]

5. Guerreiro, J.; Proença, J.; Ferreira, J.G.; Gago, A. Experimental characterization of in-plane behaviour of old masonry walls strengthened through the addition of CFRP reinforced render. Compos. Part B Eng. 2018, 148, 14-26. [CrossRef]

6. Sweidan, R.I. The Application of Fiber Reinforced Plastics to the Strengthening of Masonry Structures. Ph.D. Thesis, Massachusetts Institute of Technology, Cambridge, MA, USA, December 1992.

7. Witzany, J.; Cejka, T.; Zigler, R. Problems of masonry strengthening with carbon- and glass fibre fabric. Procedia Eng. 2011, 14, 2086-2093. [CrossRef]

8. Gams, M.; Tomaževič, M.; Berset, T. Seismic strengthening of brick masonry by composite coatings: An experimental study. Bull. Earthq. Eng. 2017, 15, 4269-4298. [CrossRef]

9. Olivito, R.S.; Tedesco, A.; Codispoti, R.; Spadea, G. Strengthening Strategies of a Historical Masonry Construction. Key Eng. Mater. 2014, 624, 627-634. [CrossRef]

10. Konthesingha, K.M.C.; Masia, M.J.; Petersen, R.B.; Mojsilovic, N.; Simundic, G.; Page, A.W. Static cyclic in-plane shear response of damaged masonry walls retrofitted with NSM FRP strips-An experimental evaluation. Eng. Struct. 2013, 50, 126-136. [CrossRef]

11. Oliveira, D.V.; Basilio, I.; Lourenço, P.B. Experimental Bond Behavior of FRP Sheets Glued on Brick Masonry. J. Compos. Constr. 2011, 15, 32-41. [CrossRef]

12. Valluzzi, M.R.; Oliveira, D.V.; Caratelli, A.; Castori, G.; Corradi, M.; De Felice, G.; Garbin, E.; Garcia, D.; Garmendia, L.; Grande, E.; et al. Round Robin Test for composite-to-brick shear bond characterization. Mater. Struct. Constr. 2012, 45, 1761-1791. [CrossRef]

13. Foraboschi, P. Strengthening of Masonry Arches with Fiber-Reinforced Polymer Strips. J. Compos. Constr. 2004, 8, 191-202. [CrossRef]

14. Khan, H.A.; Nanda, R.P.; Das, D. In-plane strength of masonry panel strengthened with geosynthetic. Constr. Build. Mater. 2017, 156, 351-361. [CrossRef]

15. Shermi, C.; Dubey, R.N. Study on out-of-plane behaviour of unreinforced masonry strengthened with welded wire mesh and mortar. Constr. Build. Mater. 2017, 143, 104-120. [CrossRef]

16. Kariou, F.A.; Triantafyllou, S.P.; Bournas, D.A.; Koutas, L.N. Out-of-plane response of masonry walls strengthened using textile-mortar system. Constr. Build. Mater. 2018, 165, 769-781. [CrossRef]

17. Maljaee, H.; Ghiassi, B.; Lourenço, P.B. Bond behavior in NSM-strengthened masonry. Eng. Struct. 2018, 166, 302-313. [CrossRef]

18. Bruggi, M.; Taliercio, A. Topology Optimization of the Fiber-Reinforcement of No-Tension Masonry Walls. Key Eng. Mater. 2017, 747, 36-43. [CrossRef]

19. Jasieńko, J.; Logoń, D.; Misztal, W. Trass-lime reinforced mortars in strengthening and reconstruction of historical masonry walls. Constr. Build. Mater. 2016, 102, 884-892. [CrossRef]

20. Di Tommaso, A.; Focacci, F.; Micelli, F. Strengthening Historical Masonry with FRP or FRCM: Trends in Design Approach. Key Eng. Mater. 2017, 747, 166-173. [CrossRef] 
21. Corradi, M.; Di Schino, A.; Borri, A.; Rufini, R. A review of the use of stainless steel for masonry repair and reinforcement. Constr. Build. Mater. 2018, 181, 335-346. [CrossRef]

22. Azmee, N.M.; Shafiq, N. Ultra-high performance concrete: From fundamental to applications. Case Stud. Constr. Mater. 2018, 9. [CrossRef]

23. Zhou, M.; Lu, W.; Song, J.; Lee, G.C. Application of Ultra-High Performance Concrete in bridge engineering. Constr. Build. Mater. 2018, 186, 1256-1267. [CrossRef] 